\title{
Perioperative factors associated with hyperglycemia after pediatric cardiac surgery and impact of hyperglycemia on morbidity and mortality
}

\author{
Çağlar Ödek ${ }^{1}$, Tanıl Kendirli${ }^{1}$, Nihan Yıldırım-Yıldız², Ayhan Yaman ${ }^{1}$, Tayfun Uçar ${ }^{3}$, \\ Zeynep Eyileten ${ }^{4}$, Can Ateş ${ }^{5}$, Adnan Uysalel ${ }^{3}$, Ercan Tutar ${ }^{3}$, Semra Atalay ${ }^{3}$ \\ Divisions of ${ }^{1}$ Pediatric Critical Care, ${ }^{3}$ Pediatric Cardiology, ${ }^{2}$ Department of Pediatrics; ${ }^{4}$ Department of Pediatric Cardiovascular \\ Surgery, ${ }^{5}$ Department of Biostatistics, Ankara University Faculty of Medicine, Ankara, Turkey. \\ E-mail: caglar_odek@hotmail.com \\ Received: 2nd January 2017, Revised: 10th November 2017, Accepted: 9th December 2017
}

SUMMARY: Ödek Ç, Kendirli T, Yıldırım-Yıldız N, Yaman A, Uçar T, Eyileten Z, Ateş C, Uysalel A, Tutar E, Atalay S. Perioperative factors associated with hyperglycemia after pediatric cardiac surgery and impact of hyperglycemia on morbidity and mortality. Turk J Pediatr 2018; 60: 497-505.

This retrospective, observational, single-center study aimed to determine the perioperative factors associated with postoperative hyperglycemia (blood glucose level $\geq 126 \mathrm{mg} / \mathrm{dl}$ ) and the impact of hyperglycemia on morbidity and mortality in a cohort of children undergoing cardiac surgery. Non-diabetic children aged between 1 month to 18 years who were consecutively admitted to pediatric intensive care unit (PICU) after cardiac surgery for congenital heart disease between January 2008 and December 2013 were included. One hundred and twenty-six patients were qualified for inclusion during the study period. Seventy-four $(57.8 \%)$ of the patients had at least one glucose measurement $\geq 126 \mathrm{mg} / \mathrm{dl}$. Higher PRISM III-24 (OR 1.1, 95\% CI 1.02$1.18, \mathrm{p}=0.004)$ and PELOD $(\mathrm{p}=0.006)$ scores, higher Wernovsky inotropic score $(p=0.027)$ and vasoactive-inotropic score $(p=0.029)$ were associated with hyperglycemia. Postoperative hyperglycemia was not associated with duration of mechanical ventilation), length of PICU stay, healthcare associated infections, or mortality. Our study establishes that hyperglycemia is common after pediatric cardiac surgery but not associated with short-term morbidity and mortality. Insulin therapy can be accomplished without hypoglycemia when a permissive glycemic target is used. A large prospective multiple institution trial is necessary to facilitate defined guidelines for postoperative hyperglycemia after pediatric cardiac surgery.

Key words: cardiac surgery, congenital heart disease, hyperglycemia, hypoglycemia, insulin.

The data was presented at the 12th Congress of Pediatric Emergency Medicine and Intensive Care, with International Participation, 15-19 April 2015, Antalya, Turkey.

Critically ill children admitted into a pediatric intensive care unit (PICU) were commonly found to exhibit hyperglycemia due to an inflammation-mediated increased endogenous glucose production and decreased utilization resulting from insulin resistance. ${ }^{1}$ Hyperglycemia also develops after pediatric cardiac surgery and the incidence of hyperglycemia reaches to more than $90 \%$ in some reports. ${ }^{2-4}$
Hyperglycemia has been associated with poor outcomes in children with traumatic brain injuries, respiratory failure, septic shock, severe burn injuries, and general critical illness. ${ }^{1}$ However, studies regarding the association between hyperglycemia and postoperative outcomes for pediatric cardiac surgery patients have conflicting results. Some retrospective studies have shown a relationship between hyperglycemia and adverse outcomes ${ }^{2-5}$, whereas others showed that hyperglycemia was not detrimental.6,7 A recent prospective cohort study showed that elevated postoperative glucose levels did not adversely affect 4-year 
neurodevelopmental outcome in children operated for congenital heart disease ${ }^{8}$. Also, two multi-center prospective randomized trials reported that tight glycemic control after cardiac surgery in children had no significant effect on major clinical outcomes. ${ }^{9,10}$ So, the management of hyperglycemia in the postoperative period remains controversial.

In the current study, our primary aim was to determine the perioperative factors associated with hyperglycemia after pediatric cardiac surgery. Our secondary aim was to determine whether there is an association between postoperative hyperglycemia and infection rates, duration of mechanical ventilation (MV), length of PICU stay, and mortality.

\section{Material and Methods}

\section{Setting and patients}

Our institution is a tertiary-care training children's hospital with an 8-bed PICU and approximately 300 patients are annually admitted to our unit. We performed a retrospective cohort study of non-diabetic children aged between 1 month to 18 years who were consecutively admitted to our PICU after cardiac surgery for congenital heart disease between January 2008 and December 2013. We excluded patients undergoing a cardiac surgical procedure that could not be classified using the Risk Adjustment in Congenital Heart Surgery-1 (RACHS-1) category. ${ }^{11} \mathrm{We}$ also excluded patients with missing data.

\section{Study definitions and data collection}

We considered hyperglycemia a blood glucose measurement $\geq 126 \mathrm{mg} / \mathrm{dl}$, based on the 2006 American Diabetes Association definition. ${ }^{12} \mathrm{We}$ further stratified the severity of hyperglycemia into mild (126-199 mg/dl) and severe $(\geq 200$ $\mathrm{mg} / \mathrm{dl}$ ). Duration of hyperglycemia was assessed by calculating the number of hours to exposure to a glucose level $\geq 126 \mathrm{mg} / \mathrm{dl}$. Hypoglycemia was defined as mean blood glucose level of $<50 \mathrm{mg} / \mathrm{dl} .{ }^{13}$ Duration of MV was defined as the cumulative duration of ventilation during the entire PICU stay. Organ failure criteria were defined as shown in Table I.

Preoperative data included: age, sex, weight, failure to thrive (weight below the 3 th percentile for age), diagnosis, and RACHS-1 category.
Intraoperative data included: presence of cardiopulmonary bypass (CPB), CPB time (CPBT), cross-clamp time (CCT), and use of systemic glucocorticoids.

Postoperative data included: Pediatric Risk of Mortality III-24 (PRISM III-24) ${ }^{15}$ and Pediatric Logistic Organ Dysfunction (PELOD) ${ }^{16}$ scores, Wernovsky inotropic score (IS) ${ }^{17}$ (dopamine dose $[\mu \mathrm{g} / \mathrm{kg} / \mathrm{min}]+$ dobutamine dose $[\mu \mathrm{g} /$ $\mathrm{kg} / \mathrm{min}]+100 \mathrm{x}$ epinephrine dose $[\mu \mathrm{g} / \mathrm{kg} /$ min]), vasoactive-inotropic score (VIS) ${ }^{18}$ (IS $+10 \times$ milrinone dose $[\mu \mathrm{g} / \mathrm{kg} / \mathrm{min}]+$ $10,000 \mathrm{x}$ vasopressin score $[\mathrm{U} / \mathrm{kg} / \mathrm{min}]+100$ $\mathrm{x}$ norepinephrine dose $[\mu \mathrm{g} / \mathrm{kg} / \mathrm{min}])$, arterial blood lactate levels, number of organ failure, systemic inflammatory response syndrome (SIRS), blood glucose level (BGL), presence of hyperglycemia, duration of hyperglycemia, requirement for intravenous infusion of regular human insulin, presence of hypoglycemia, duration of MV, length of PICU stay, occurrence of healthcare-associated infections, and outcomes. PELOD, IS, VIS, blood lactate levels, and number of organ failure data were collected at PICU admission.

Postoperative maintenance fluids, glucose monitoring and management of hyperglycemia

The dextrose content of postoperative intravenous fluids is typically $5 \%$ dextrose. Blood glucose levels were measured with a bedside blood glucose meter (Accu-Chek Active, Roche, USA and On Call Advanced, ACON Laboratories, Inc. San Diego, USA). Details of glucose monitoring and management of hyperglycemia were shown in Figure 1.

The Institutional Review Board approved the study before data collection began and waived

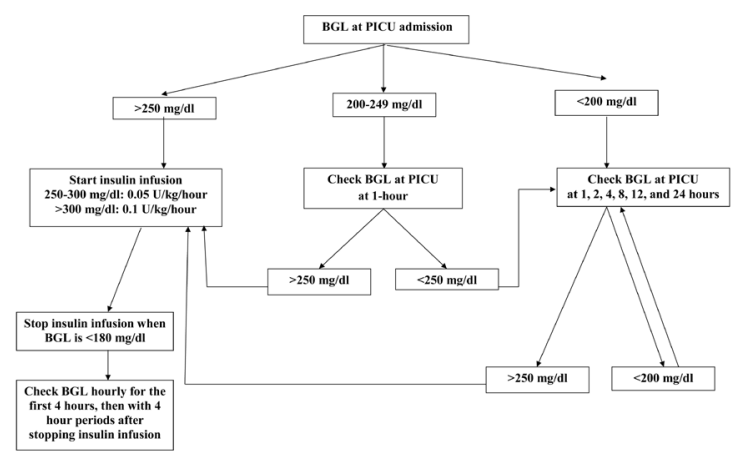

Fig. 1. Details of glucose monitoring and management of hyperglycemia. BGL: blood glucose level 
the requirement for written informed consent.

\section{Statistical analysis}

Data are presented as mean \pm SD or median (minimum-maximum) for continuous variables and as frequencies (percentage) for categorical variables. In order to test whether the data were normally distributed, the KolmogorovSmirnov and Shapiro-Wilk tests were used. Continuous variables were compared using Student's t-test or the Mann-Whitney U test and categorical variables were compared using chi-square or Fisher's exact test, as appropriate. Logistic regression analyses were performed to seek unadjusted relationships between perioperative, intraoperative, and postoperative variables and hyperglycemia. Odds ratios with 95\% confidence intervals (CI) were calculated. Multivariable models were chosen using a forward-selection process with inclusion criteria of $p<0.05$. Statistical analyses were performed by using SPSS 15.0 for Windows and $p$ values less than 0.05 were considered as statistically significant.

\section{Results}

During the study period, 131 consecutive patients were admitted to PICU after cardiac surgery. Excluding five patients with missing data, 126 patients qualified for inclusion in the study.

\section{Preoperative variables}

The median age of the study population was
10 (1.5-168) months. Forty-nine percent of patients were male. The mean weight of patients was $8.5 \pm 5.01(2-30) \mathrm{kg}$ and $42 \%$ of them had failure to thrive. Ventricular septal defect repair was the most common procedure $(n=39,30.9 \%)$ followed by tetralogy of Fallot repair $(n=21,16.6 \%)$, atrioventricular septal defect repair $(n=11,8.7 \%)$, and atrial septal defect closure $(n=10,7.9 \%)$. For the total cohort of the patients, $17.4 \%$ were RACHS-1 category $1,64.2 \%$ were category $2,17.4 \%$ were category 3 , and $0.7 \%$ were category 4 . Type of cardiac lesions, procedures, and RACHS-1 categories are shown in Table II.

\section{Intraoperative variables}

One hundred and three $(81.7 \%)$ patients underwent CPB. Mean CPBT and CCT were $105.87 \pm 39.83(22-222)$ and $69.5 \pm 28.91$ (14168) mins, respectively. All patients who underwent $\mathrm{CPB}$ were given a single intravenous dose of methylprednisolone $1 \mathrm{mg} / \mathrm{kg}$ after induction of anesthesia.

\section{Postoperative variables}

Mean PELOD and PRISM III-24 scores were $11.15 \pm 7.14(0-43)$ and 9.69 \pm 6.09 (0-39), respectively. Median VIS and IS scores were $15(0-170)$ and $10(0-125)$, respectively. The mean level of blood lactate level at PICU admission was $4.74 \pm 3.10(0.7-18) \mathrm{mmol} / \mathrm{L}$. Median number of organ failure was 2 (0-6). Systemic inflammatory response syndrome was seen in $63(50 \%)$ patients.

Table I. Organ System Failure Criteria. ${ }^{14}$

\begin{tabular}{|c|c|}
\hline Cardiovascular & $\begin{array}{l}\mathrm{BP}<5^{\text {th }} \text { percentile for age or systolic } \mathrm{BP}<2 \mathrm{SD} \text { below normal age or need } \\
\text { for vasoactive drug to keep } \mathrm{BP} \text { in normal range or } \geq 2 \text { of the following: } \\
\text { Base deficit }>5.0 \mathrm{mEq} / \mathrm{L} \\
\text { Lactic acidosis more than twice the upper limit of normal } \\
\text { Urine output }<0.5 \mathrm{ml} / \mathrm{kg} / \text { hour } \\
\text { Capillary refill }>5 \mathrm{~second} \\
\text { Core to peripheral temperature gap }>3^{\circ} \mathrm{C}\end{array}$ \\
\hline Neurologic & GCS score $\leq 11$ or decrease in GCS $\geq 3$ points from abnormal baseline \\
\hline Hematologic & Platelet count $<80,000 / \mathrm{mm}^{3}$ or INR $>2$ \\
\hline Renal & $\begin{array}{l}\text { Serum creatinine } \geq 2 \text { times the upper limit of normal for age or two fold } \\
\text { increase in baseline creatinine }\end{array}$ \\
\hline Hepatic & Total bilirubin $\geq 4 \mathrm{mg} / \mathrm{dl}$ or ALT twice upper limit of normal \\
\hline Respiratory & $\begin{array}{l}\mathrm{PaO}_{2} / \mathrm{FiO}_{2}<300 \text { in absence of cyanotic congenital heart disease or } \\
\text { preexisting lung disease or } \mathrm{PaCO}_{2}>65 \text { torr or } 20 \text { torr over baseline or } \\
\mathrm{FiO}_{2}=0.50 \text { to keep saturations } \geq 92 \% \text { or need for invasive or noninvasive } \\
\text { mechanical ventilation }\end{array}$ \\
\hline
\end{tabular}

ALT: alanine aminotransferase; BP: blood pressure; GCS: Glasgow Coma Scale; INR: international normalized ratio; SD: standard deviation 
Seventy-four $(57.8 \%)$ of the patients had at least one glucose measurement $\geq 126 \mathrm{mg} / \mathrm{dl}$. Severe hyperglycemia were shown in $66.2 \%$ of these hyperglycemic patients. The median onset time of hyperglycemia was 1 (1-24) hour and $83.7 \%(62 / 74)$ of these patients were hyperglycemic at the time of PICU admission. Forty-eight $(64.8 \%)$ of hyperglycemic patients received insulin infusion. The mean level of BGL at the beginning time of insulin infusion was $278.6 \pm 46.19 \mathrm{mg} / \mathrm{dl}$. The mean duration of hyperglycemia was $4.29 \pm 2.72$ (1-12) hours and the mean amount of insulin administered during hyperglycemia was $0.16 \pm 0.1(0.05-0.6)$ $\mathrm{U} / \mathrm{kg} /$ hour. No episode of hypoglycemia was seen during study period.

The median duration of MV was 21 hours (0-888) and median length of PICU stay was 4 (1-45) days. Six (4.7\%) patients died in PICU. Healthcare-associated infections occurred in $3(2.3 \%)$ patients and all were ventilatorassociated pneumonia.

\section{Perioperative Factors Associated with} Postoperative Hyperglycemia

Perioperative variables for hyperglycemic and normoglycemic groups are shown in Table III. By univariate analysis, higher PRISM III-24 $(\mathrm{p}=0.004)$ and PELOD $(\mathrm{p}=0.006)$ scores, higher IS $(p=0.027)$ and VIS $(p=0.029)$ were associated with hyperglycemia. When combined into a multivariate model, we found higher PRISM III-24 score (OR, 1.1; 95\% CI 1.02-1.18; $\mathrm{p}=0.004)$ was significantly associated with postoperative hyperglycemia in the multivariate logistic regression model.

\section{Outcomes}

Postoperative hyperglycemia was not associated with duration of MV $(p=0.840)$, length of PICU stay $(p=0.299)$, healthcare associated infections $(p=0.569)$, or mortality $(p=0.690)$.

\section{Discussion}

In this study, we confirmed that hyperglycemia is a common event after pediatric cardiac

Table II. Cardiac Lesions and Type of Procedures.

\begin{tabular}{|c|c|c|c|}
\hline Cardiac lesions & Procedures & RACHS-1 category & $\mathrm{N}$ \\
\hline VSD & VSD closure & 2 & 39 \\
\hline \multirow[b]{2}{*}{ TOF } & Pulmonary banding & 3 & 2 \\
\hline & TOF repair & 2 & 21 \\
\hline Complete AVSD & AVSD repair & 3 & 11 \\
\hline Secundum ASD & ASD closure & 1 & 10 \\
\hline ASD+VSD & ASD+VSD closure & 2 & 9 \\
\hline PDA & PDA ligation & 1 & 8 \\
\hline \multirow{3}{*}{ Pulmonary atresia } & BT-shunt & 3 & 5 \\
\hline & Glenn procedure & 2 & 3 \\
\hline & Fontan procedure & 3 & 2 \\
\hline $\mathrm{VSD}+\mathrm{PDA}$ & VSD closure+PDA ligation & 2 & 3 \\
\hline Coarctation of aorta & Coarctation of aorta repair & 1 & 3 \\
\hline Subaortic ridge & Subaortic ridge resection & 2 & 2 \\
\hline TAPVR & TAPVR repair & 2 & 2 \\
\hline VSD+PAPVR & PAPVR repair+VSD closure & 2 & 1 \\
\hline ASD+PAPVR & PAPVR repair+ASD closure & 1 & 1 \\
\hline ALCAPA syndrome & Coronary switch & 3 & 1 \\
\hline Double aortic arch & Double aortic arch repair & 2 & 1 \\
\hline Aortic interruption & Homograph patch augmentation & 4 & 1 \\
\hline Supravalvular aortic stenosis & Extended aortoplasty & 3 & 1 \\
\hline
\end{tabular}

ALCAPA: anomalous left coronary artery from the pulmonary artery; ASD: atrial septal defect; AVSD: atrioventricular septal defect; BT: Blalock-Taussig; PAPVR: partial anomalous pulmonary venous return; PDA: patent ductus arteriosus; TAPVR: total anomalous pulmonary venous return; TOF: tetralogy of Fallot; VSD: ventricular septal defect; 
surgery. Although different cut-off values were defined for hyperglycemia in different studies, the incidence of hyperglycemia has been reported to range from 43 to $98 \% .^{2,6}$ Similar to those studies, $57.8 \%$ of our patients were hyperglycemic and $66.2 \%$ of these patients had severe hyperglycemia.

There are limited data about perioperative factors associated with hyperglycemia after pediatric cardiac surgery. Alaei et al. ${ }^{19}$ showed that perioperative factors such as age, height, weight, pump time, and inotropic score were not associated with hyperglycemia. Rossano et al. ${ }^{7}$ reported that lower body weight and preoperative inotrope use were associated with hyperglycemia. In a retrospective observational study, Moga et al. ${ }^{3}$ showed that $<31$ days and 5-10 years age groups, preoperative prostaglandins, MV, cyanosis, higher Aristotle score, longer CPBT, deep hypothermic circulatory arrest, and perioperative steroids were associated with hyperglycemia. In our study, by univariate analysis higher PRISM III-24 and PELOD scores, higher IS and higher VIS were associated with postoperative hyperglycemia. In a multivariate model, higher PRISM III-24 score was significantly associated with postoperative hyperglycemia.

PELOD is the most frequently used score aiming to describe the severity of cases of multiple organ failure (MOF). The relationship between mortality and number of dysfunctioning organs is stronger than that with presence or absence of MOF${ }^{16}$. PRISM III-24 score is unique in that it can predict both mortality and length of stay in PICU ${ }^{15}$. Our data indicated that both PELOD and PRISM III-24 are associated with postoperative hyperglycemia after pediatric cardiac surgery. One possible explanation for this may be that these scoring systems show the severity of illness and patients with more severe diseases have higher risk for developing postoperative hyperglycemia. One can argue that presence of a BGL above $200 \mathrm{mg} / \mathrm{dl}$ is a variable of PRISM III-24 score and this may adversely affect the statistical analysis in this study. However, the PRISM III score has 17 physiologic variables subdivided into 26 ranges and the difference in PRISM III-24 score between hyperglycemic and normoglycemic patients is still significant when we exclude BGL variable.
Most of the children undergoing cardiac surgery require inotropic support after $\mathrm{CPB}$ especially those with compromised ventricular function. The degree of inotropic support is defined by Wernovsky IS and VIS.17,18 The amount of inotropic support after cardiac surgery is a marker of illness severity and increasing doses are associated with increased morbidity and mortality ${ }^{18}$. Previous studies showed that exogenously administered catecholamines in the postoperative period have been linked to the development of insulin resistance and hyperglycemia. ${ }^{20}$ Similar to those studies, our results showed that there was a significant difference in IS and VIS between normoglycemia and hyperglycemia groups and higher scores were associated with hyperglycemia.

Surgery, with its associated stress response, increases the counter-regulatory hormones (epinephrine, glucagon, growth hormone, and cortisol) and causes hyperglycemia. This is further complicated by the insulin resistance found in cardiac surgery patients associated with $\mathrm{CPB}^{21}$. Cardiopulmonary bypass activates SIRS which results in insulin resistance and hyperglycemia. ${ }^{22}$ Activation of systemic inflammation is explained with several possible mechanisms including contact of the blood with the surface of CPB circuit, mechanical shear stress as the blood passes through suction systems and filters, tissue ischemia and reperfusion, hypotension and hemodilution, administration of blood products, and hypothermia. ${ }^{23}$ The incidence of SIRS varies from $22-38 \% .{ }^{24,} 25$ Different from those studies SIRS was seen in $50 \%$ of our patients. We suggest that the high incidence of SIRS in our study was related with the low dose of glucocorticoid given at the beginning of the CPB when compared with other studies (1 $\mathrm{mg} / \mathrm{kg}$ vs. $20-30 \mathrm{mg} / \mathrm{kg}$ methylprednisolone). Previous studies showed that both CPB and CPBT were associated with postoperative hyperglycemia. ${ }^{19,23}$ In contrast to those studies, neither CPB nor CPBT were associated with postoperative hyperglycemia in our study. However $83.7 \%(62 / 74)$ of our patients were hyperglycemic at the time of PICU admission. We concluded that postoperative hyperglycemia after pediatric cardiac surgery may be associated with stress response related with surgery and intraoperatively administered exogenous catecholamines rather than $\mathrm{CPB}$ and CPBT. 
Table III. Results of Univariable Analyses for Preoperative, Intraoperative, and Postoperative Variables.

\begin{tabular}{|c|c|c|c|c|}
\hline Variables & $\begin{array}{l}\text { All patients } \\
(\mathrm{N}=126)\end{array}$ & $\begin{array}{l}\text { Normoglycemic } \\
\text { group }(\mathrm{N}=52)\end{array}$ & $\begin{array}{l}\text { Hyperglycemic group } \\
\qquad(\mathrm{N}=74)\end{array}$ & $\mathrm{p}$ value \\
\hline \multicolumn{5}{|l|}{ Preoperative } \\
\hline Age, months & $10(1.5-168)$ & $10(1.5-168)$ & $10(1.5-120)$ & 0.278 \\
\hline Sex, M/F & $62 / 64$ & $25 / 27$ & $37 / 37$ & 0.832 \\
\hline Weight, kg & $7(2.07-30)$ & $7.35(3-30)$ & $7(2.07-25)$ & 0.328 \\
\hline Failure to thrive, $\mathrm{n}(\%)$ & $53(42.1)$ & $24(46.2)$ & $29(39.2)$ & 0.436 \\
\hline \multicolumn{5}{|l|}{ RACHS-1 category, n (\%) } \\
\hline & $22(17.5)$ & $8(15.4)$ & $14(18.9)$ & \\
\hline & $81(64.3)$ & $35(67.3)$ & $46(62.2)$ & 0.783 \\
\hline & $22(17.5)$ & $9(17.3)$ & $13(17.6)$ & \\
\hline & $1(0.8)$ & - & $1(1.4)$ & \\
\hline \multicolumn{5}{|l|}{ Intraoperative } \\
\hline $\mathrm{CPB}, \mathrm{n}(\%)$ & $103(81.7)$ & $45(86.5)$ & $58(78.4)$ & 0.243 \\
\hline Glucocorticoids, n (\%) & $103(81.7)$ & $45(86.5)$ & $58(78.4)$ & 0.243 \\
\hline CPBT, minute & $100(22-222)$ & $91(38-222)$ & $105.5(22-190)$ & 0.951 \\
\hline CCT, minute & $63(14-168)$ & $63(21-168)$ & $67(14-147)$ & 0.757 \\
\hline \multicolumn{5}{|l|}{ Postoperative } \\
\hline PRISM III-24 score & $9(0-39)$ & $7.5(0-24)$ & $11(0-39)$ & 0.004 \\
\hline PELOD score & $11(0-43)$ & $11(0-22)$ & $11(0-43)$ & 0.006 \\
\hline VIS & $15(0-170)$ & $11.25(0-125)$ & $20(0-170)$ & 0.029 \\
\hline IS & $10(0-125)$ & $8(0-98)$ & $15(0-125)$ & 0.027 \\
\hline Lactate, $\mathrm{mmol} / \mathrm{L}$ & $4.1(0.7-18)$ & $3.6(0.7-16.4)$ & $4.2(1.1-18)$ & 0.247 \\
\hline Number of organ & $2(0-6)$ & $2(0-5)$ & $2(0-6)$ & 0.291 \\
\hline \multicolumn{5}{|l|}{ Failure, n (\%) } \\
\hline $\begin{array}{l}\text { Cardiovascular } \\
\text { Respiratory }\end{array}$ & $124(98.4)$ & $51(98.1)$ & $73(98.6)$ & 1.000 \\
\hline Renal & $47(37.3)$ & $18(34.6)$ & $29(39.2)$ & 0.601 \\
\hline Hepatic & $13(10.3)$ & $6(11.5)$ & 7 (9.5) & 0.706 \\
\hline Hematologic & $25(19.8)$ & $7(13.5)$ & $18(24.3)$ & 0.132 \\
\hline Neurologic & $2(1.6)$ & $0(0.0)$ & $2(2.7)$ & 0.511 \\
\hline SIRS, n (\%) & $63(50)$ & $22(42.3)$ & $41(55.4)$ & 0.148 \\
\hline Duration of MV (hour) & $20(1-480)$ & $18(1-24)$ & $48(25-480)$ & $<0.05$ \\
\hline Infection, n (\%) & $3(2.4)$ & $2(3.8)$ & $1(1.4)$ & 0.569 \\
\hline Length of PICU stay, days & $4(1-45)$ & $3(1-45)$ & $4.2(1-39)$ & 0.299 \\
\hline Mortality, n (\%) & $6(4.8)$ & $3(5.8)$ & $3(4.1)$ & 0.690 \\
\hline
\end{tabular}

Data is presented as $\mathrm{n}$ (\%) or median (minimum-maximum).

CCT: cross-clamp time; CPB: cardiopulmonary bypass; CPBT: cardiopulmonary bypass time; NIV: noninvasive ventilation; PHT: pulmonary hypertension; IS: inotropic score; PELOD: pediatric logistic organ dysfunction; PICU: pediatric intensive care unit; PRISM: pediatric risk of mortality; RACHS-1: the risk adjustment for congenital heart surgery-1; SIRS: systemic inflammatory response syndrome; VIS: vasoactive inotropic score;

Hyperglycemia is a well-known side effect of glucocorticoid use. Children undergoing cardiac surgery receive perioperative glucocorticoids to attenuate the systemic inflammatory response associated with CPB. Verhoeven et al. ${ }^{26}$ showed that treatment with glucocorticoids during surgery was the main factor associated with postoperative hyperglycemia after pediatric cardiac surgery. Moga et al. ${ }^{3}$ reported similar findings. Our patients received glucocorticoids intraoperatively at the beginning of CPB (a single dose of methylprednisolone $1 \mathrm{mg} / \mathrm{kg}$ ) and/or to treat SIRS in the postoperative period ( 2 $\mathrm{mg} / \mathrm{kg} /$ day methylprednisolone in four divided 
doses). However glucocorticoid administration was not associated with hyperglycemia in our study. One possible explanation for this may be that our patients were given lower doses of glucocorticoids when compared with patients in studies mentioned above (1-2 $\mathrm{mg} / \mathrm{kg}$ vs. 20-30 mg/kg methylprednisolone).

Previous studies regarding the association between hyperglycemia and postoperative outcomes for pediatric cardiac surgery patients have conflicting results. Yates et al. ${ }^{5}$ showed that the peak glucose level and duration of hyperglycemia in the immediate postoperative period were associated with increased morbidity and mortality. They also showed that prolonged hyperglycemia was associated with increased length of PICU and CICU stay, and increased duration of MV. ${ }^{5}$ Polito et al. ${ }^{27}$ reported that perioperative glycemic derangement was associated with poor outcomes and they concluded that the ideal BGL may be 110 to $126 \mathrm{mg} / \mathrm{dl}$. Falcao et al. ${ }^{4}$ concluded that the duration of hyperglycemia is significantly associated with postoperative morbidities and increased mortality. In a prospective cohort study, Alaei et al. ${ }^{19}$ reported that patients with severe hyperglycemia (>200 mg/dl) showed a higher mortality rate and more morbidities. In contrast to these studies, Rossano et al. ${ }^{7}$ showed that hyperglycemia was not detrimental in infants who have undergone cardiac surgery. They concluded that infants with BGLs between 80 and $100 \mathrm{mg} / \mathrm{dl}$ were at increased risk for adverse events. ${ }^{7}$ Lou et al. ${ }^{6}$ found similar results. In a recent study, Krueger et al. ${ }^{8}$ reported that hyperglycemia has no adverse effect on 4-year neurodevelopmental outcome in children operated for congenital heart disease. In our study, postoperative hyperglycemia was not associated with duration of MV, length of PICU stay, healthcare associated infections, and mortality. However, our study cohort consists of low-risk patients and these patients usually have shorter durations of MV, length of PICU stay, and lower mortality rates. We suggest that high-risk patient groups may have different results.

As previous studies provide conflicting evidence about the association between hyperglycemia and morbidity and mortality, the management of hyperglycemia in the postoperative period remains controversial. There is still a considerable debate about the optimum target range for BGL after pediatric cardiac surgery. In a randomized trial in critically ill children, three quarters of whom were cardiac surgery patients, Vlasselaers et al. ${ }^{28}$ concluded that tight glycemic control was associated with a decrease in PICU stay and mortality. However, it was also associated with extremely high rates (25\%) of hypoglycemia ( $<40 \mathrm{mg} / \mathrm{dl})$ which may adversely affect the developing brain. In SPECS trial, Agus et al. ${ }^{9}$ showed that tight glycemic control (TGC) (with the use of an insulin-dosing algorithm targeting a BGL of $80-110 \mathrm{mg} / \mathrm{dl}$ ) can be achieved with a low hypoglycemia rate $(3 \%)$ after pediatric cardiac surgery, but it does not significantly change the infection rate, length of stay, measures of organ failure, or mortality as compared with standard care. In a CHiP trial, Macrae et al. ${ }^{10}$ reported that TGC (targeting a BGL of 72-126 $\mathrm{mg} / \mathrm{dl}$ ) did not have a significant effect on major clinical outcomes after pediatric cardiac surgery. Mahle $^{29}$ suggested that hyperglycemia can be considered as a common finding following pediatric cardiac surgery and one should be cautioned against overaggressive treatment of hyperglycemia. In the current study, we used a more permissive glycemic target. Insulin infusion was started when BGL exceeded 250 $\mathrm{md} / \mathrm{dl}$ and discontinued when BGL fell below $180 \mathrm{mg} / \mathrm{dl}$. No episode of hypoglycemia was seen during study period.

The present study has some limitations. The major limitation was the retrospective analysis of prospectively collected data. Another important limitation was the small size of this single-center study, which may pose barriers to the generalization of the results. Also, the study could be underpowered to identify the differences in some of the variables due to small size. RACHS-1 scores averaged 1.99 for all patients in our cohort, indicating a low-risk patient population, and our findings may not translate to populations with higher RACHS-1 scores. Also, we were unable to account for differences in carbohydrate administration during intraoperative and postoperative period, including glucose infusion from maintenance fluids and feeding regimens. Finally, this study was not designed to determine whether postoperative hyperglycemia predicts long-term, particularly neurodevelopmental, outcomes. 
In conclusion, hyperglycemia is common after pediatric cardiac surgery but not associated with short-term morbidity and mortality. Higher PRISM III-24 and PELOD scores, higher IS and VIS were associated with postoperative hyperglycemia indicating that children with more severe diseases have higher risk for developing hyperglycemia after cardiac surgery. Our study establishes that insulin therapy can be accomplished without hypoglycemia when a permissive glycemic target was used. However, postoperative hyperglycemia (both peak glucose level and duration of hyperglycemia) was not associated with short-term morbidity and mortality so the need for insulin infusions can be questioned. As there is no clear consensus on the optimal range of postoperative BGL and the management of hyperglycemia, a large prospective multiple institution trial is necessary to facilitate defined guidelines for postoperative hyperglycemia after pediatric cardiac surgery.

\section{REFERENCES}

1. Ulate KP, Zimmerman JJ. Common endocrinopathies in the pediatric intensive care unit. In: Fuhrman BP, Zimmerman J, Carcillo JA, Clark RS, Rotta AT, Tobias JD, Relvas MS, Thompson AE (eds). Pediatric Critical Care (4th ed). Philadelphia: Elsevier, 2011: 1105-1123.

2. Ulate KP, Falcao GC, Bielefeld MR, Morales JM, Rotta AT. Strict glycemic targets need not to be so strict: a more permissive glycemic range for critically ill children. Pediatrics 2008; 122: e898-e904.

3. Moga MA, Manlhiot C, Marwali EM, McCrindle BW, Van Arsdell GS, Schwartz SM. Hyperglycemia after pediatric cardiac surgery: Impact of age and residual lesions. Crit Care Med 2011; 39: 266-272.

4. Falcao G, Ulate K, Kouzekanani K, Bielefeld MR, Morales JM, Rotta AT. Impact of postoperative hyperglycemia following surgical repair of congenital cardiac defects. Pediatr Cardiol 2008; 29: 628-636.

5. Yates AR, Dyke PC 2nd, Taeed R, et al. Hyperglycemia is a marker for poor outcome in the postoperative pediatric cardiac patient. Pediatr Crit Care Med 2006; 7: 351-355.

6. Lou S, Ding F, Long C, Jinping Liu, Ju Zhao, Zhengyi Feng. Effects of peri-operative glucose levels on adverse outcomes in infants receiving open-heart surgery for congenital heart disease with cardiopulmonary bypass. Perfusion 2011; 26: 133-139.

7. Rossano JW, Taylor MD, Smith EO, et al. Glycemic profile in infants who have undergone the arterial switch operation: Hyperglycemia is not associated with adverse events. J Thorac Cardiovasc Surg 2008; 135: 739-745.
8. Krueger JJ, Brotschi B, Balmer C, Bernet V, Latal B. Postoperative hyperglycemia and 4-year neurodevelopmental outcome in children operated for congenital heart disease. J Pediatr 2015; 167: 12531258.

9. Agus MS, Steil GM, Wypij D, et al.; SPECS Study Investigators. Tight glycemic control versus standard care after pediatric cardiac surgery. N Engl J Med 2012; 367: 1208-1219.

10. Macrae D, Grieve R, Allen E, et al.; CHiP Investigators. A randomized trial of hyperglycemic control in pediatric intensive care. N Engl J Med 2014; 370: 107-118.

11. Jenkins KJ. Risk adjustment for congenital heart surgery: the RACHS-1 method. Semin Thorac Cardiovasc Surg Pediatr Card Surg Annu 2004; 7: 180-184.

12. American Diabetes Association. Diagnosis and classification of diabetes mellitus. Diabetes Care 2005; 28(Suppl 1): S37-S42.

13. Langdon DR, Stanley CA, Sperling MA. Hypoglycemia in the toddler and child. In: Sperling MA (ed). Pediatric Endocrinology (4th ed). Philadelphia: Elsevier, 2014: 920-955.

14. Goldstein B, Giroir B, Randolph A; International Consensus Conference on Pediatric Sepsis. International pediatric sepsis consensus conference: definitions for sepsis and organ dysfunction in pediatrics. Pediatr Crit Care Med 2005; 6: 2-8.

15. Pollack MM, Patel KM, Ruttimann UE. PRISM III: an updated pediatric risk of mortality score. Crit Care Med 1996; 24: 743-752.

16. Leteurtre S, Martinot A, Duhamel A, et al. Validation of the Paediatric Logistic Organ Dysfunction (PELOD) score: prospective, observational, multicenter study. Lancet 2003; 362: 192-197.

17. Wernovsky G, Wypij D, Jonas RA, et al. Postoperative course and hemodynamic profile after the arterial switch operation in neonates and infants: A comparison of low-flow cardiopulmonary bypass and circulatory arrest. Circulation 1995; 92: 2226-2235.

18. Gaies MG, Gurney JG, Yen AH, et al. Vasoactiveinotropic score as a predictor of morbidity and mortality in infants after cardiopulmonary bypass. Pediatr Crit Care Med 2010; 11: 234-238.

19. Alaei F, Davari PN, Alaei M, Azarfarin R, Soleymani E. Postoperative outcome for hyperglycemic pediatric cardiac surgery patients. Pediatr Cardiol 2012; 33: 21-26.

20. Ulate KP, Raj S, Rotta AT. Critical illness hyperglycemia in pediatric cardiac surgery. J Diabetes Sci Technol 2012; 6: 29-36.

21. Gaynor JW, Berkowitz DH. Cardiac bypass for repair of congenital heart disease in infants and children. In: Fuhrman BP, Zimmerman J, Carcillo JA, Clark RS, Rotta AT, Tobias JD, Relvas MS, Thompson AE (eds). Pediatric Critical Care (4th ed). Philadelphia: Elsevier, 2011: 379-400.

22. Floh AA, Manlhiot C, Redington AN, et al. Insulin resistance and inflammation are a cause of hyperglycemia after pediatric cardiopulmonary bypass surgery. J Thorac Cardiovasc Surg 2015; 150: 498-504.e1. 
23. de Betue CT, Verbruggen S, Schierbeek H, et al. Does a reduced glucose intake prevent hyperglycemia in children early after cardiac surgery? A randomized controlled crossover study. Critical Care 2012; 16: R176.

24. Güvener M, Korun O, Demirtürk OS. Risk factors for systemic inflammatory response after congenital cardiac surgery. J Card Surg 2015; 30: 92-96.

25. Boehne M, Sasse M, Karch A, et al. Systemic inflammatory response syndrome after pediatric congenital heart surgery: Incidence, risk factors, and clinical outcome. J Card Surg 2017; 32: 116-125.

26. Verhoeven JJ, Hokken-Koelega AC, den Brinker M, et al. Disturbance of glucose homeostasis after pediatric cardiac surgery. Pediatr Cardiol 2011; 32: 131-138.
27. Polito A, Thiagarajan RR, Laussen PC, et al. Association between intraoperative and early postoperative glucose levels and adverse outcomes after complex congenital heart surgery. Circulation 2008; 118: 2235-2242.

28. Vlasselaers D, Milants I, Desmet L, et al. Intensive insulin therapy for patients in paediatric intensive care: A prospective, randomised controlled study. Lancet 2009; 373: 547-556.

29. Mahle WT. A little sugar never hurt anyone: Hyperglycemia after infant heart surgery. J Pediatr 2015; 167: 1185-1186. 